\title{
EXPERIÊNCIAS E SABERES DE PROFESSORES UNIVERSITÁRIOS EM RELAÇÃO À INCLUSÃO DE ALUNOS COM DEFICIÊNCIA NA EDUCAÇÃO SUPERIOR
}

\author{
David dos Santos Calheiros" \\ Neiza de Lourdes Frederico Fumes**
}

\begin{abstract}
RESUMO
$\mathrm{O}$ artigo tem o objetivo de descrever e analisar as experiências de professores da Universidade Federal de Alagoas em relação a pessoas com deficiência, como ainda aspectos de sua formação e as estratégias pedagógicas já conhecidas e utilizadas para o atendimento desse público. Utilizamos a abordagem qualitativa e a entrevista semiestruturada, com caráter reflexivo, realizada com oito docentes. A análise empregada foi a de conteúdo, especificamente a temática. Os resultados mostraram que poucos docentes tiveram experiências com pessoas com deficiência e que eles não tinham uma formação específica em educação inclusiva. Ademais, parte dos docentes descreveu realizar escassas e tímidas, mas necessárias, estratégias pedagógicas para atender as necessidades do alunado com deficiência. Assim, deve haver maior investimento na formação do professor universitário, uma vez que ano após ano ampliam-se as matrículas de alunos com deficiência no ensino superior.
\end{abstract}

Palavras-chave: Educação superior. Formação docente. Inclusão educacional. Educação especial.

\begin{abstract}
EXPERIENCE AND KNOWLEDGE OF PROFESSORS ON THE INCLUSION OF TERTIARY STUDENTS WITH DISABILITIES IN THE HIGHER EDUCATION

The article aims to describe and analyze the experiences of professors of the Federal University of Alagoas in relation to people with disabilities, but also regarding the aspects of their training and teaching strategies already known and used to attend this public. We used a qualitative approach and a semi-structured interview, with reflective character, which was held with the participation of eight professors. The content analysis was applied considering, specifically, the theme. The results showed that few professors have had experience with people with disabilities and that they had no specific training on inclusive education. In addition, other ones reported the adoption of scarce and shy, but necessary, teaching strategies to meet the needs of the students with disabilities. Thus, it should be encouraged greater investment in training
\end{abstract}

\footnotetext{
* Doutorando na área de Educação Especial pela Universidade Federal de São Carlos (UFSCar). Professor da Universidade Estadual de Ciências da Saúde de Alagoas (Uncisal). E-mail: davidcalheiros@hotmail.com

** Doutora em Ciências do Desporto e Educação Física pela Universidade do Porto. Docente do Programa de Pós-graduação em Educação Brasileira da Universidade Federal de Alagoas (UFAL). E-mail: neizaf@yahoo.com
} 
the professor of the universities, since year after year the enrolment of students with disabilities in higher education is increasing.

Keywords: Higher education. Teacher training. Educational inclusion. Special education.

\section{RESUMEN}

\section{LAS EXPERIENCIAS Y LOS CONOCIMIENTOS DE LOS PROFESORES UNIVERSITARIOS EN RELACIÓN A LA INCLUSIÓN DEL ALUMNADO CON DISCAPACIDAD EN LA EDUCACIÓN SUPERIOR}

El artículo tiene como objetivo describir y analizar las experiencias de los profesores de la Universidad Federal de Alagoas en relación con las personas con discapacidad, sino también los aspectos de sus estrategias de formación y enseñanza ya conocidos y utilizados para asistir a este público. Se utilizó un enfoque cualitativo y una entrevista semiestructurada, con carácter reflexivo, se llevó a cabo con ocho profesores. El análisis se empleó a contenido, específicamente el tema. Los resultados mostraron que algunos profesores han tenido experiencia con personas con discapacidad y que no tenían ninguna formación específica en educación inclusiva. Además, algunos maestros descritos realizan estrategias escasos y tímidos, pero necesarias de enseñanza para satisfacer las necesidades del alumnado con discapacidad. Por lo tanto, uno debe ser una mayor inversión en la formación del profesor universitario, ya que año tras año para ampliar la matrícula de los estudiantes con discapacidad en la educación superior.

Palabras clave: Educación superior. Formación del profesorado. Inclusión educativa. Educación especial.

\section{INTRODUÇÃO}

Notamos nos dias atuais uma crescente preocupação por parte de órgãos governamentais e da sociedade civil organizada para que a educação seja um direito de todos os cidadãos, inclusive aqueles cidadãos que possuem alguma deficiência e que estiveram historicamente alijados da escola. Essa apreensão tem sido expressa em vários documentos internacionais: Declaração de Jomtien (ORGANIZAÇÃO DAS NAÇÕES UNIDADES PARA A EDUCAÇÃO, A CIÊNCIA E A CULTURA, 1990), Declaração de Salamanca (ORGANIZAÇÃO DAS NAÇÕES UNIDADES PARA A EDUCAÇÃO, A CIÊNCIA E A CULTURA, 1994), Convenção Internacional dos Direitos da Pessoa com Deficiência (ORGANIZAÇÃO DAS NAÇÕES UNIDAS, 2006) e na nossa própria Constituição Federal de 1988 (BRASIL, 1988). ${ }^{1}$

1 Especificamente em seu artigo 205, é definido que "a educação, direito de todos e dever do Estado e da família, será promovida e incentivada com a colaboração da sociedade, visando ao pleno desenvolvimento da pessoa, seu preparo para o exercício da cidadania
No caso da pessoa com deficiência, vale insistir que essas transformações em favor de uma educação para todos são particularmente importantes, considerando que, por muito tempo, essas pessoas foram deixadas à margem da sociedade, sendo impedidas de participar do contexto educativo e do convívio social. De acordo com Pletsch (2014), essa evolução no atendimento educacional das pessoas com deficiência, primordialmente, está pautada no reconhecimento delas enquanto cidadãs plenas de direitos e deveres sociais iguais e inalienáveis. Mais especificamente no contexto brasileiro, pode-se assegurar que tanto os estudos científicos, quanto as políticas públicas e ações governamentais para a educação especial/inclusiva são bastante recentes e ainda mais o são na educação superior.

De uma maneira geral, nas últimas quatro décadas muito se tem debatido sobre as possibilidades

e sua qualificação para o trabalho". 
educativas e os modelos para a educação das pessoas com deficiência na realidade brasileira. Dentre estes, podemos destacar dois paradigmas que se constituíram neste período: o da integração e o da inclusão escolar, os quais possuem concepções distintas de educação e, consequentemente, sobre a forma de atender a diversidade humana e valorizar as potencialidades existentes.

Por um lado, a perspectiva da integração escolar propugnava que o aluno deveria se adaptar ao funcionamento escolar, sendo ele o responsável pela a sua própria permanência na instituição (PRIETO, 2013). Em contrapartida, o paradigma da inclusão escolar defende que é dever da instituição escolar adaptar-se às necessidades educacionais de seus alunos com deficiência (MATOS; MENDES, 2014). A perspectiva da inclusão respeita a integridade humana e procura garantir os instrumentos necessários para a aprendizagem da pessoa com deficiência, possibilitando-a, dessa maneira, não só o acesso ao ambiente educacional, mas, também, promovendo a sua permanência e a aprendizagem com qualidade e sucesso.

Ainda sobre a inclusão, Nogueira (2010) afirma que por ser um modelo ainda hodierno tanto a produção científica como as políticas públicas de educação inclusiva concentram-se mais na esfera da educação básica. Contudo, nos últimos anos, já percebermos uma substancial ampliação da abrangência dessas produções científicas, como também algumas (é verdade que ainda insuficientes) ações governamentais para viabilizar a inclusão da pessoa com deficiência na educação superior.

A respeito dessas políticas voltadas para a inclusão da pessoa com deficiência na educação superior, Moreira (2014) asseguram-nos que é a partir da década de 1990 que são aprovados e emitidos um número considerável de dispositivos legais, sob a forma de leis, decretos, portarias e resoluções, que tratam da inclusão da pessoa com deficiência na educação superior, da formação profissional para o atendimento das necessidades educacionais especiais de pessoas com deficiência, da formação necessária ao professor-instrutor, tradutor e intérprete de Libras, bem como da inclusão de Libras como disciplina curricular obrigatória em vários cursos de graduação (Pedagogia, Letras, licenciaturas de uma forma geral, dentre outras).
Sobre esses dispositivos legais, podemos mencionar a título de ilustração: a Portaria $\mathrm{n}^{\circ}$ 1.793/1994, que recomenda a inclusão da disciplina "Aspectos Ético-Político-Educacionais da Normalização e Integração da Pessoa Portadora de Necessidades Especiais", prioritariamente, nos cursos de Pedagogia, Psicologia e demais licenciaturas; o Aviso Circular no 277/1996 (BRASIL, 1996b), que propõe modificações que atendam às necessidades educacionais de pessoas com deficiência durante o processo seletivo das instituições de educação superior; a Portaria ${ }^{\circ}$ 3.284/2003 (BRASIL, 2003), que dispõe sobre os requisitos de acessibilidade para os processos de autorização e de reconhecimento de cursos, e de credenciamento de instituições; o Decreto $n^{\circ}$ 5.626/2005 (BRASIL, 2005), que institui Libras como disciplina curricular obrigatória nos cursos de formação de professores, entre outros.

Mesmo com os avanços nos marcos legais em vigor no país, Drago (2013) chama atenção para o fato de que há uma incompatibilidade entre o que está posto na lei e o que se efetiva no cotidiano. Isto porque a prática concretizada na maioria dos espaços educacionais, inclusive nas instituições de educação superior, não contempla a aprendizagem e o desenvolvimento das potencialidades dos alunos. Neste sentido, é necessário compreender que a inclusão educacional, em nosso país, está ainda em seus primeiros passos e há um longo caminho a ser construído, principalmente no que diz respeito à educação superior e ao papel da docência nesse nível de ensino.

Como parte desse processo, é preciso repensar a formação pedagógica dos professores universitários, uma vez que tem sido priorizado, quase que exclusivamente, o conhecimento técnico da área de atuação. E, em grande parte, ser professor na educação superior é uma improvisação e a repetição de práticas já vivenciadas. A própria Lei de Diretrizes e Bases da Educação Nacional (LDB), de 1996, estabelece no artigo 65 que "A formação docente, exceto para a educação superior, incluirá a prática de ensino de, no mínimo, trezentas e sessenta horas", permitindo-nos ponderar que para este profissional a prática de ensino não se constitui em um elemento necessário a sua atividade profissional. E determina no artigo 66 que: "A preparação para o exercício do magistério superior far-se-á em 
nível de pós-graduação, prioritariamente em programas de mestrado e doutorado", cujo objetivo é a formação de pesquisadores em uma área específica e não possui nenhum dispositivo legal que define como obrigatória a oferta de disciplinas de caráter pedagógico (BRASIL, 1996a).

Concordamos com Neuenfeldt (2006) que considera que a formação para a Educação Superior é fundamental, importante e inquestionável, no entanto os profissionais que atuam nessa área hoje são "preparados" apenas pelos cursos de pós-graduação, em que é priorizada uma formação para a pesquisa, tornando os pós-graduandos estritamente pesquisadores e especialistas em seus temas de estudo. Mediante esta situação, perguntamos: como engenheiros, médicos, advogados, entre outros profissionais, tornam-se professores na educação superior? Como os processos de ensino e aprendizagem são significados por estes profissionais? Este descaso com a formação pedagógica do professor da educação superior também pode ser constatada nos editais de concursos públicos, que a cada dia que passa exigem critérios mais elevados em termos de formação acadêmica e de produtividade científica, mas que não incluem critérios relacionados à profissionalidade docente (OLIVEIRA; VASCONCELOS, 2011).

No que se refere ao trabalho docente na educação superior, o debate pedagógico em torno da inclusão educacional questiona não somente a formação deste profissional acerca da área em questão, mas também a postura que este professor deve assumir diante da diversidade (CASTRO, 2011). Vale ressaltar que a discussão sobre a docência universitária e a inclusão de pessoas com deficiência na educação superior é algo complexo e atual.

As pesquisas têm indicado que os docentes universitários, além de não se sentirem preparados para atender as demandas do processo educacional inclusivo, apresentam resistência para mudar ou adaptar suas práticas pedagógicas a fim de facilitar a participação e proporcionar melhores condições de escolarização ao aluno com deficiência, conforme relatam Bueno (2013) e Marques e Gomes (2014).

Também é possível verificar, em outros estudos, que os docentes universitários, mesmo tendo fragilidades na formação inicial para atender as de- mandas do processo inclusivo, têm buscado suprir as necessidades da diversidade discente por meio de recursos/esforços próprios e, muitas das vezes, sem um serviço de suporte institucional (CASTRO, 2011; NOGUEIRA; NOGUEIRA, 2014).

Diante desse cenário, entendemos que a posição que o professor assume no processo formativo desenvolvido na educação superior envolvendo pessoas com deficiência constitui-se em um dos aspectos que poderão tornar estes ambientes educacionais inclusivos (ou não) ${ }^{2}$, pois é das suas atitudes e práticas pedagógicas que, muitas das vezes, o aprendizado do aluno depende. Cabe destacar que estes profissionais são responsáveis pela elaboração de vários componentes curriculares, a saber: ementas das disciplinas, objetivos de ensino, conteúdos programáticos, procedimentos metodológicos, recursos de ensino e vários aspectos avaliativos (GATTI; BARRETTO; ANDRÉ, 2011; PERES et al., 2013).

Desse modo, é necessário que, nessas atribuições docentes, a diversidade humana seja considerada e, sobretudo, contemplada em sua concretude. Além disso, concordamos com Novais (2010) que afirma que na relação professor-aluno não há lugar para imprevistos e desconhecimentos. Diante disso, torna-se essencial que todo professor que atua em instituições de ensino superior tenha os conhecimentos necessários para atender as necessidades educacionais especiais dos alunos com deficiência, visto que estes podem a qualquer momento adentrar a sua sala de aula.

No caso específico dos docentes dos cursos de licenciaturas, este processo deve ser visto ainda com mais cuidado, uma vez que nestes espaços educacionais as discussões relativas à inclusão deveriam ser mais acirradas, considerando que estes cursos têm o compromisso de formar os profissionais que irão atuar na educação básica, onde o número de alunos com deficiência é cada vez maior. Sendo assim, torna-se urgente que a formação profissional para o magistério contemple a compreensão da diversidade do alunado, bem

\footnotetext{
2 No entanto, gostaríamos de reforçar que o professor não pode ser visto como o único responsável por esse processo. Em qualquer nível que ocorra, a inclusão implica em profundas mudanças na organização institucional, remodelação do modelo educativo e pedagógico, entre outras, as quais estão muito além das possibilidades de ação do professor.
} 
como o desenvolvimento de habilidades que permitam o acolhimento da diversidade em sala de aula (DUEK, 2011). Contudo, para que isto aconteça parece ser importante formar o formador também, o que implica em rever crenças e valores arraigados que, além de serem familiares (OLIVEIRA, 2009; SILVA, 2014), parecem tão verdadeiros e evidentes, tornando-se, aparentemente, impossíveis de serem modificados. Além disso, mudanças implicam na necessidade de se conhecer limites e deficiências na própria atuação profissional.

Considerando o fato de que o professor desempenha um papel-chave no processo educativo, o objetivo desta pesquisa foi descrever e analisar as experiências de professores da Universidade Federal de Alagoas em relação a pessoas com deficiência, assim como aspectos de sua formação e as estratégias pedagógicas já conhecidas e utilizadas para o atendimento desse público.

\section{ASPECTOS METODOLÓGICOS}

Optamos por utilizar uma abordagem qualitativa de pesquisa por esta ter como um dos seus fundamentos a ideia que a construção social das realidades em estudo deve estar "interessada nas perspectivas dos participantes, em suas práticas do dia a dia e em seu conhecimento do cotidiano relativo à questão do estudo" (FLICK, 2009, p. 16).

Para conhecer a perspectiva dos participantes, no caso dos docentes da educação superior, iniciamos com um mapeamento daqueles que lecionavam para 20 universitários com deficiência que estavam regularmente matriculados em um dos cursos de licenciatura da Universidade Federal de Alagoas (campus Maceió) e indicados pela Pró-reitoria de Graduação. Para isso, os universitários foram contatados por um dos pesquisadores e deste procedimento foi verificado que apenas 04 deles apresentavam deficiências mais significativas e que exigiam um olhar mais próximo do professor e modificações em aspectos metodológicos das disciplinas cursadas.

No passo seguinte, identificamos as disciplinas cursadas pelos alunos e, por conseguinte, os docentes das disciplinas em que tais alunos indicavam ter mais dificuldades -13 docentes no total. Todos eles foram contatados e 08 deles aceitaram participar da pesquisa. A razão pela qual os cinco professores não participaram do estudo relacionava-se com a dificuldade de encontrar tempo em suas agendas de trabalho devido à sobrecarga de atribuições que lhe eram designadas enquanto professores universitários, às ausências e desmarcações recorrentes de entrevistas que haviam sido agendadas antecipadamente pelos próprios docentes - que foram justificadas por eles em razão do surgimento de compromissos imprevistos de trabalho. Além disso, notamos a aparente falta de interesse desses docentes em discutir o tema em questão. Tais acontecimentos também estiveram presentes nos relatos da pesquisa de Barbosa (2011).

A etapa seguinte foi a realização das entrevistas, executadas com apoio em um roteiro - que foi previamente elaborado para este fim de pesquisa. Apesar disso, apresentava características da entrevista semiestruturada e teve caráter reflexivo. De acordo com Yunes e Szymanski (2005), a proposta da entrevista reflexiva permite entender a subjetividade da fala do entrevistado, favorecendo a construção de um conhecimento novo, nos limites da representatividade da fala e na busca de uma horizontalidade nas relações de poder.

As entrevistas ocorreram de forma individual (nas salas dos próprios professores - que eram ambientes reservados, confortáveis e sem a presença de terceiros), tendo o seu conteúdo gravado (em áudio) na íntegra por intermédio de um gravador de voz, sendo logo depois transcritas literalmente para que este material fosse utilizado posteriormente para análise dos dados. É importante dizer que as entrevistas iniciavam-se após o docente ser informado sobre os objetivos, os procedimentos, a forma de participação e os riscos e os benefícios da pesquisa, entre outros aspectos, finalizando com a assinatura do Termo de Consentimento Livre e Esclarecido. Por conta da garantia de anonimato dos participantes, todos os nomes utilizados são fictícios.

Empregamos a análise de conteúdo, especificamente a temática, que é um dos procedimentos clássicos para analisar material de origem textual. Esse tipo de análise tende a valorizar o material a ser tratado, principalmente por poder fazer contextualização com os fatos sociais e históricos nos quais foram produzidos (BARDIN, 2011). 
Para aplicar a análise de conteúdo, realizamos uma leitura exaustiva dos materiais coletados, a fim de fazer um delineamento dos temas importantes para o estudo. Em seguida, houve exploração dos potenciais de codificações baseadas em critérios temáticos. Desses procedimentos geraram-se as seguintes categorias: As experiências dos docentes com pessoas com deficiência em diferentes instâncias e momentos de sua vida; A formação dos professores em relação ao atendimento das necessidades educacionais da pessoa com deficiência; As estratégias pedagógicas já conhecidas e utilizadas pelo docente para atender aos alunos com deficiência. Cada uma destas categorias será descrita e discutida na seção de resultados.

A realização dessa pesquisa teve início após a aprovação do projeto pelo Comitê de Ética em Pesquisa com seres humanos da Universidade Federal de Alagoas, sob o parecer de $n^{\circ} 011360 / 2010-68$.

\section{RESULTADOS E DISCUSSÃO}

Para uma melhor compreensão deste estudo, faz-se necessário apresentar alguns aspectos a mais dos participantes da pesquisa. Nomeadamente, os professores entrevistados graduaram-se entre 1971 e 2009, e uma considerável parte deles lecionava em cursos de graduação da área de Exatas (Matemática e Física), com exceção de três professores, que ministravam aulas nos cursos de História. Nestes cursos estavam regularmente matriculados: um universitário com deficiência física (Licenciatura Matemática), um universitário com baixa visão (Licenciatura em História), uma universitária com deficiência auditiva (Licenciatura em Física) e o outro universitário com deficiência visual (Licenciatura em Física).

Vejamos o que os professores nos disseram sobre suas experiências, formação e estratégias metodológicas já conhecidas para atender a diversidade.

\section{As experiências dos docentes com pessoas com deficiência em diferentes instâncias e momentos de sua vida}

Para melhor compreender a atividade docente na perspectiva da educação inclusiva e as estratégias pedagógicas utilizadas pelos docentes para atender as necessidades educacionais das pessoas com deficiência, encontramos nas histórias de vida um elemento primordial para realizar tal análise. Como afirma Novais (2010), o trabalho dos professores é ele próprio, ancorado nesse mundo vivencial, do qual extrai seu sentido para aqueles e aquelas que o realizam. Dessa forma, o professor pode ter a sua formação e suas estratégias pedagógicas influenciadas pela sua existência.

Para Nóvoa (1992), compreender a história de vida de professores vai além de dar voz ao sujeito e descrever fatos da esfera da vida humana, mas permite ver o sujeito em relação à história de seu tempo. Isto possibilita ao professor novas perspectivas de ver, pensar e fazer o seu trabalho docente. É uma tarefa de olhar para o passado, compreender o contexto político, social e cultural, e construir uma ação futura, a partir dos fatos diagnosticados e das reais possibilidades de mudanças.

Cabe dizer que nesta pesquisa não utilizamos o método História de vida em si, apenas procuramos recuperar aspectos da história de vida pessoal e profissional dos participantes da pesquisa, em que a pessoa com deficiência esteve presente (ou não), para que, desse modo, pudéssemos melhor compreender a sua prática pedagógica atual, uma vez que os saberes provenientes das experiências podem ser seu constituinte.

No caso particular dos docentes participantes da pesquisa, verificamos que as experiências de vida envolvendo pessoas com deficiência concentravam-se principalmente no sistema educacional, excetuando um professor que teve uma relação mais extensa, em seu círculo de amizades, e outra professora que teve experiências em seu contexto familiar. No que se refere às experiências docentes com as pessoas com deficiência no sistema educacional, notamos que muitas delas se concretizaram especificadamente na educação superior e nos anos mais recentes, como podemos observar nos recortes que se seguem:

No curso de História, eu dei aula a mais ou menos uns 6 ou 7 alunos [com deficiência] no máximo, na totalidade que eu me lembre, porque, às vezes, alguns alunos podem até ser e não pretendem [assumir a sua deficiência]. [...] Mesmo que a legislação os proteja. (Professor Célio). 
Semestre passado tive um aluno [com deficiência]. Ele acabou desistindo [do curso de Física]. Ele falou que iria desistir porque iria mudar de curso. Ele iria mudar para Engenharia. (Professor Ricardo).

Além desses professores, um dos docentes universitários teve a oportunidade de lecionar em uma instituição escolar de educação básica para turmas com alunos com deficiências matriculados, como podemos visualizar a seguir:

O que eu me recordo é que a primeira experiência que eu tive de fato [com as pessoas com deficiência] foi quando fui professor de uma escola de educação básica, em 2007. (Professor Emanuel).

Esses resultados levam-nos a pensar que essas experiências são decorrentes da crescente participação da pessoa com deficiência no contexto escolar. De acordo com o Censo Escolar do ano de 2014, haviam matriculados em escolas comuns 698.768 alunos público-alvo ${ }^{3}$ da Educação Especial (INSTITUTO NACIONAL DE ESTUDOS E PESQUISAS EDUCACIONAIS ANÍSIO TEIXEIRA, 2015).

Entre os docentes entrevistados e que haviam lecionado para pessoas com deficiência no sistema educacional regular, entendemos que não necessariamente as suas experiências possuíram um caráter inclusivo. Pois, como verificaremos a seguir, as experiências vivenciadas pelos professores com pessoas com deficiência no âmbito escolar não foram consideradas positivas pela maioria deles. Como exemplo disso, o Professor Emanuel relatou a seguinte situação envolvendo uma aluna com deficiência intelectual:

Ela era DM [uma pessoa com deficiência mental] ${ }^{4}$ e ninguém [do corpo institucional] sabia lidar com ela. Nem eu. Então, a gente simplesmente ignorava, porque ou você dava aula para os 60 [alunos] que tinha na turma ou você dava aula só para ela. Você tinha que optar. Infelizmente, você tinha que fazer a seleção. [...] E durante esses dois anos [que a aluna esteve na instituição], em nenhum momento houve um espaço [na escola de educação básica que tra-

3 O público-alvo da Educação Especial envolve as pessoas que possuem deficiência, transtornos globais do desenvolvimento e altas habilidades/superdotação (BRASIL, 2008).

4 Atualmente, o termo a ser empregue é deficiência intelectual (AMERICAN ASSOCIATION ON INTELLECTUAL AND DEVELOPMENTAL DISABILITIES, 2010), no entanto preservamos a fala do professor. balhava] para que eu construísse alguma discussão na escola ou fora dela sobre o assunto. Não existia oportunidade. (Professor Emanuel).

Embora a opção desse professor à época tenha sido pela maioria dos alunos, não podemos simplesmente criticá-lo por essa atitude e desconsiderar o contexto educativo em que professor e aluno estavam inseridos. Concordamos com Tardif e Lessard (2007, p. 81), que apontam que "é preciso levar em conta também o surgimento das estruturas burocráticas e de instâncias ou poderes internos e externos à escola que, de um modo ou de outro, controlam o trabalho docente ou interferem sobre ele".

Sem dúvida alguma, essas estruturas tornam o processo de inclusão da pessoa com deficiência muito mais complexo, podendo, inclusive, impedir ou dificultar que o seu direito, no caso à educação, possa ser garantido, com qualidade. Apesar disso, consideramos que as instituições educacionais não poderão continuar ignorando o que ocorre ao seu redor, marginalizando e privando as diferenças humanas de progredirem academicamente. Impõe-se que estas instituições revejam o seu papel no processo de inclusão e contribuam no processo de formação continuada de seu corpo docente. Atuando desta maneira, a escola estará mais instrumentalizada e apta para enfrentar a exclusão educacional e garantir que a educação seja para todos.

Retomando as experiências dos docentes entrevistados, especificamente aqueles que tiveram, além da profissional, uma experiência familiar ou em seu círculo de amizades com pessoas com deficiências, notamos que suas atitudes eram mais condizentes com a valorização das habilidades individuais de seus alunos com deficiência. Ressaltamos também que estes docentes afirmavam que se sentiam mais preparados para atuar justamente com as pessoas que tinham a mesma deficiência ou uma deficiência similar à de suas experiências anteriores. Sobre este assunto, Xavier (2014) afirma que as experiências e vivências pessoais estabelecidas em um determinado momento histórico da vida dão significado à trajetória profissional. Neste caso específico, as experiências constituídas pelos docentes, com determinados tipos de deficiências, pareciam favorecer o seu exercício profissional com pessoas que apresentavam o mesmo tipo de deficiência. 
Entretanto, as dificuldades em situações de ensino voltavam a se manifestar em relação às outras deficiências, cujas vivências dos professores eram mais pontuais, como podemos evidenciar logo abaixo:

Pesquisador: Você já tinha tido alguma experiência [educacional/acadêmica] com pessoas com deficiência?

Professora Solange: Tive. Tive aluno surdo, em BH [Belo Horizonte]. Tive uma aluna cega e tive um aluno cadeirante.

Pesquisador: Como foram as experiências com essas pessoas com deficiências?

Professora Solange: Olha, com o cadeirante foi muito tranquilo. Agora meu pai é deficiente e pode ser que seja por aí também, porque aí eu sei como lidar. Com o aluno cego e com o aluno que era surdo foi que foi mais difícil.

Diante desses relatos, corroboramos com o pensamento de Nóvoa (1992) ao afirmar que os aspectos sociais vivenciados pelos docentes se apresentam irrevogavelmente associados à prática, atuando certamente na dinâmica da formação profissional e das estratégias pedagógicas, o que seguramente irá influenciar no processo de ensino-aprendizagem dos acadêmicos. Neste sentido, acreditamos que quando os professores vivenciam experiências significativas com alunos com deficiência, haverá maior possibilidade de que estes estruturem melhores práticas pedagógicas, levando em consideração as necessidades educacionais das pessoas com deficiência. Isso acontecerá principalmente quando os docentes não forem envolvidos em processos formativos em suas instituições e as suas práticas pedagógicas continuarem a ser orientadas pelos saberes experienciais (TARDIF, 2007), como parece ser recorrente nas instituições de educação superior.

\section{A formação dos professores em relação ao atendimento das necessidades educacionais da pessoa com deficiência}

É inquestionável o papel do professor no processo educativo, no entanto, a emergência do paradigma da educação inclusiva tem provocado questionamentos sobre sua atuação no que se refere ao atendimento das necessidades educacionais dos alunos com deficiência (BUENO, 2013; CASTRO, 2011; DUEK, 2011). Relacionado a estas novas demandas cada vez mais se tem exigido do professor uma formação e uma prática profissional que estejam alicerçadas nos princípios da inclusão educacional nos diferentes níveis de ensino.

No caso específico dos docentes entrevistados, verificamos que quatro deles tinham formação em nível de doutorado, três em mestrado e apenas um especialista. Essa formação especializada dos participantes é compatível com o que vem sendo exigido para o exercício do magistério superior nas universidades públicas brasileiras nos últimos anos, e que também é prescrito pela Lei de Diretrizes e Bases da Educação Nacional, de 1996 (BRASIL, 1996), que estabelece que as universidades devam ter um terço, pelo menos, do seu corpo docente com a titulação acadêmica de mestrado e doutorado. Entretanto, a respeito do nível de formação acadêmica, conseguimos apreender que esta, ainda que seja um elemento primordial, não implica na realização de uma prática pedagógica que contemple a diversidade do alunado, como bem expressa um dos sujeitos de nossa pesquisa:

Não existe uma formação para ser professor de ensino superior. Não existe! Você faz mestrado, doutorado, mas você faz em uma área específica. Você não se forma para ser professor. (Professor Ricardo).

Infelizmente, essa não é uma situação exclusiva da universidade em estudo. Beraldo (2009) considera que essa falta de preocupação com a formação deste profissional tem algumas causas, como, por exemplo: a) a crença de que para ser professor universitário é preciso ter conhecimento aprofundado da disciplina a ser ministrada; b) a cisão entre ensino e pesquisa; c) a falta de um acompanhamento mais rigoroso dos órgãos governamentais da formação do docente universitário; d) o interesse incipiente dos pesquisadores pelo tema; e, e) a falta de clareza do que significa docência na educação superior.

Essa despreocupação com a formação pedagógica do professor universitário inquieta-nos ainda mais quando se refere à sua formação para 
o atendimento das necessidades educacionais dos alunos com deficiência. De uma maneira particular, os dados obtidos mostram-nos que nenhum dos participantes da pesquisa mencionou ter no seu percurso de formação acadêmica alguma (in) formação sobre a educação da pessoa com deficiência. Este quadro colabora com a compreensão das razões pelas quais uma parcela significativa dos profissionais participantes admitiu não saber trabalhar com os alunos que possuíam deficiência em sua sala de aula, como podemos visualizar nos relatos dos entrevistados:

Eu não sabia o que fazer com ele, como ensinar Física para um aluno surdo. Se ensinar Física para um aluno 'normal' já é complexo, imagine você ensinar Física para um aluno surdo? (Professor Emanuel).

Se a deficiência for auditiva [...] eu não teria experiência para tratar [...] não sei como me comunicar. Não conheço Sinais, Libras. (Professor Antônio).

Essa lacuna identificada na formação dos docentes entrevistados da Universidade Federal de Alagoas na perspectiva da educação inclusiva é explicada por eles próprios pela ausência de conhecimentos específicos sobre a área em questão. $\mathrm{O}$ que constitui um fator preocupante no que concerne à construção de uma escola para todos, pois esses professores que atuam na educação superior têm como um dos desafios de sua profissão atender indistintamente a todos os seus alunos. Além disso, eles estão incumbidos de formar as novas gerações de professores para atuar na educação básica em uma perspectiva de educação para todos, o que significa ensinar a todos, sem distinção.

Em meio a essa situação, vale destacar que a fragilidade da formação docente na perspectiva da educação inclusiva não é algo tão novo no cenário educacional brasileiro e já tem suscitado pontuais aprovações de orientações legais para os cursos superiores no sentido de suprir essa carência. Exemplificando isto, temos a Portaria $n^{\circ} 1.793 / 1994$, que destaca a necessidade de complementar os currículos de formação de profissionais que atuam com pessoas com deficiência com a inclusão de uma disciplina que trate sobre aspectos éticos, políticos e educacionais dessas pessoas, prioritariamente nos cursos de Pedagogia, Psicologia e em todas as licenciaturas (BRASIL, 1994).
Mesmo havendo essa incipiente preocupação com a formação docente desde os meados dos anos 1990, poucas mudanças ocorreram efetivamente neste sentido na educação superior. Chacon (2004) constatou que nem todos os profissionais que se formaram a partir da publicação da referida Portaria tiveram uma disciplina relativa à educação inclusiva, de maneira que chegou a ponderar que este documento acabou por ser esquecido por muitas instituições de ensino superior. Semelhantemente aos resultados obtidos por Chacon (2004), constatamos que dos 8 professores que participaram desta pesquisa, 5 deles se graduaram em um período posterior à publicação da Portaria no 1.793/1994, contudo nenhum deles afirmou ter conhecimentos a respeito da educação inclusiva em suas disciplinas curriculares da graduação.

É necessário ainda compreender que, mesmo com a relevância de se ter uma disciplina específica sobre aspectos relacionados à educação inclusiva na matriz curricular dos cursos de ensino superior, não podemos restringir a responsabilidade de todo $o$ processo de formação na perspectiva inclusiva para esta disciplina e desconsiderar o aspecto transdisciplinar que deve envolver o ambiente acadêmico. Para Cruz e Costa (2015), a perspectiva transdisciplinar tem como responsabilidade estabelecer elos de comunicações entre as disciplinas, de modo que os conteúdos possam ser trabalhados de forma transversal em todo o currículo de formação dos professores. Nesse sentido, a responsabilidade por trabalhar conteúdos sobre a inclusão educacional não seria mérito de apenas uma única disciplina, mas, de igual modo, de todas as outras.

Retomando a discussão a respeito da fragilidade da formação dos professores da Universidade Federal de Alagoas na perspectiva da educação inclusiva, conseguimos entender que este não é um problema apenas dos professores dessa Universidade, que não receberam (in)formação sobre conteúdos relativos à educação inclusiva durante sua graduação e pós-graduação, mas que arremete à atividade docente de diversos outros profissionais/professores de nosso país, comprometendo a efetivação do paradigma inclusivo.

Verificamos ainda, nesta categoria temática, que alguns dos professores participantes buscaram conhecer um pouco sobre a temática da educação 
inclusiva através de: cursos, eventos, palestras e mesmo consultas com pessoas especializadas na área. No entanto, destacamos que tal fato só veio acontecer depois que alguns destes docentes tiveram a experiência de lecionar para alunos com deficiência e se viram confrontados com o "problema". As falas dos sujeitos abaixo expressam o que mencionamos:

Eu fui à busca do curso de LIBRAS. Foi uma necessidade minha. Fiz Braile também, mas o Braile que eu fiz também foi um minicurso que teve lá na Bienal [do Livro de Alagoas]. Acho que de 4 horas. Coisa pouca, mas também porque eu não tive aluno cego. Não tive aluno. É com alunos com deficiências tão gritantes que eu precisasse buscar, entendeu? (Professor Emanuel).

E, por fim, veio o problema da prova, porque ela só escrevia em Braile e a escola não oferecia ninguém que lesse. Então, foi aí que eu aprendi Braile com ela. Eu disse: 'Olha, você vai me ensinar e eu vou aprender, e depois que eu aprender eu vou corrigir suas provas.' Então, no início foi muito difícil. [...] hoje eu sei ler e escrever [braile]. (Professora Solange).

Tomando ainda a formação de professores na perspectiva da educação inclusiva como foco de discussão, compreendemos que esta formação, seja na modalidade inicial ou contínua, mobiliza uma atenção maior de todo o espaço acadêmico para assegurar os direitos educacionais da pessoa com deficiência (SILVA, 2014). Apesar disso, notamos que poucas tentativas vêm sendo realizadas na Universidade Federal de Alagoas no sentido de melhorar o nível dos processos de ensino e aprendizagem, sem que, no entanto, resultados satisfatórios em termos de mudanças na prática sejam alcançados - uma vez que não há uma consistente adesão por parte dos professores em participar das ações promovidas pela Universidade em questão para o acolhimento das necessidades educacionais dos alunos com deficiência. Além disso, essas ações, quando realizadas, adquirem um caráter pontual e sem uma sistematização.

A respeito dessas tentativas de melhor atender o aluno com deficiência na Universidade Federal de Alagoas, podemos citar um curso oferecido, no ano de 2009, pelo "Núcleo de Estudo em Educação e Diversidade" (NEEDI/UFAL), que objetivava desenvolver ações que permitiam contribuir na formação continuada de professores do campus Maceió (UFAL), no que diz respeito ao atendimento em sala de aula do aluno com deficiência. Para este curso, 33 docentes universitários foram convidados formalmente, sendo que apenas 14 inscreveram-se, e apenas 1 professor compareceu e participou efetivamente das atividades programadas (CALHEIROS; BARBOSA; FUMES, 2009).

Diante disso, entendemos que não podemos ser indiferentes aos desafios educacionais, mas antes de tudo, devemos nos instrumentalizar para atender as necessidades educacionais de todos os alunos, sem exceção, que participam do processo educacional, garantindo-lhes as reais possibilidades para o desenvolvimento das suas potencialidades no cenário acadêmico e científico. Trabalhando neste sentido advirão melhores condições de atendimento educacional, nos vários níveis de ensino, inclusive na educação superior.

\section{As estratégias pedagógicas conhecidas e utilizadas pelo docente para atender aos alunos com deficiência}

Por muitos anos, o modelo de ensino tradicional baseado na transmissão de conhecimentos firmava o ambiente educacional como garantia de aprendizagem, sendo o professor o protagonista desta cena. No entanto, este caráter educacional tem sido desmistificado e, hoje, já se tem plena certeza de que ensinar não se limita a transferir conhecimentos, mas se prolonga por produzir possibilidades para a sua própria produção ou construção (FREIRE, 2011). Todavia, é preciso saber que esse modelo educacional de ensino-aprendizagem não foge à regra da proposta da educação inclusiva. Contudo, o ensino inclusivo necessita de propostas ainda mais específicas que contribuam para as mudanças educacionais.

Sabendo disso, solicitamos que os docentes da Universidade Federal de Alagoas, participantes da pesquisa, refletissem sobre as estratégias pedagógicas por eles já conhecidas e utilizadas para atender as necessidades educacionais especiais dos alunos com deficiência que estavam matriculados e frequentavam as suas disciplinas. Um dos resultados mais significativos desta pesquisa, e que 
indubitavelmente compromete o atendimento dessas necessidades, é o fato de uma parte expressiva dos docentes desta Universidade, inicialmente, ter mostrado desconhecer a presença de alunos com deficiência em suas turmas, como podemos visualizar nos trechos a seguir:

Geralmente, o aluno não me revela que tem alguma deficiência. Portanto, até agora, não sei de nenhum aluno meu, ou seja, alguma pessoa que tenha assistido às minhas aulas que tenha alguma deficiência. (Professor Antonio).

Eu não percebi, nem ele [aluno com deficiência visual] se pronunciou. [...] acho que ele usa óculos fundos. (Professor Ricardo).

O desconhecimento docente em relação à presença de alunos com deficiência nas turmas que lecionam poderá ser compreendido a partir de pelo menos duas perspectivas, as quais não se anulam, mas comprometem o desenvolvimento educacional inclusivo. O primeiro fator que chamamos atenção é a invisibilidade social e histórica das pessoas com deficiência. De acordo com Piccolo e Mendes (2013), esta se caracteriza como uma das marcas mais visíveis dos processos de exclusão. O segundo fator corresponde à inoperância dos órgãos gestores em definir e garantir políticas de inclusão ao nível da administração superior da universidade e, desse modo, dar condições para que informações a respeito do aluno com deficiência cheguem à sua unidade acadêmica, à coordenação e aos professores. Ações como essas abrem oportunidades de comunicação entre os envolvidos e possibilitam que as necessidades dos alunos sejam conhecidas e consideradas desde o início do curso até a sua conclusão (CASTRO, 2011).

Os resultados revelaram ainda que, por vezes, certos docentes entrevistados indicavam não acreditar no desenvolvimento educacional das pessoas com deficiência e reafirmaram também que não sabiam trabalhar com a diversidade humana em sua sala de aula. Vejamos os fragmentos que se seguem:

Se eu tenho um aluno com deficiência mental [na instituição educacional], para ele a aula vai ser superchata, porque vai estar além do que está esperando. No caso do autista, ou essa aula vai estar superdifícil, porque ele não consegue acompanhar, e aí vai ser $0,0,0,0,0,0$ nas avaliações. Porque é isso que vai acontecer. Então, eu realmente não sei o que fazer [...] Na minha concepção, eu sei que isso vai de encontro à inclusão, mas se estamos pensando em aprendizagem, do ponto de vista da aprendizagem, da produção de conhecimento, turmas mistas com alunos com deficiência importante [...] certamente estarão fadados a ficarem excluídos, infelizmente. (Professor Emanuel). ${ }^{5}$

Vamos pensar em um aluno cego tendo aula numa turma normal de alunos. Então, tem experimentos que fazemos aqui [no curso de Física], aulas experimentais que precisam ser visualizadas. Então, como ficaria esse deficiente visual? Pra mim, fica complicado. (Professor Antônio).

É preciso perceber que a inclusão educacional da pessoa com deficiência depende, antes de qualquer coisa, do seu reconhecimento como pessoa e das suas potencialidades, apesar de apresentar necessidades especiais (PLETSCH, 2014). No caso dos participantes da pesquisa, parece-nos que a não valorização e/ou descrédito no desenvolvimento acadêmico dos alunos com deficiência manifestos deve-se ao fato desses profissionais não estarem preparados profissionalmente para atuar com esta parcela minoritária da sociedade.

Esse resultado é consonante com os achados em um estudo realizado por Santos (2011), que procurou estudar a atividade e a formação de professores da educação superior na perspectiva da inclusão. Os resultados indicam que as atividades utilizadas em sala de aula, em grande parte, eram inadequadas e muitas delas deviam-se ao fato da insuficiência na formação acadêmica do professor, que não lhes oferecia subsídios e informações a respeito de um trabalho pedagógico com as pessoas com necessidades educacionais especiais. Silva e Pletsch (2010) complementam dizendo que a falta de preparo e informação impedem o professor de desenvolver uma prática pedagógica sensível às necessidades educacionais do aluno com deficiência.

\footnotetext{
5 Salientamos que à época da realização da pesquisa não havia na Universidade Federal de Alagoas alunos matriculados com transtornos globais do desenvolvimento e com deficiência intelectual, de maneira que a resposta do Prof. Emanuel foi balizada pelas suas experiências anteriores, as quais parecem ter sido pouco satisfatórias. Todavia, consideramos importante trazer esse recorte para o texto por ele expressar de maneira marcante uma concepção de ensino incompatível com o respeito aos diferentes níveis e estilos de aprendizagem e mesmo as impossibilidades do professor atender $o$ aluno com deficiência em suas aulas.
} 
Dada a importância que é facultada à formação docente em uma perspectiva inclusiva para o desenvolvimento de um sistema educacional que atenda a todos os alunos, entendemos que todos os professores deveriam construir saberes docentes que reflitam e compreendam as necessidades educacionais especiais das pessoas com deficiência. Da mesma forma, acreditamos que todos os profissionais que se interessam pela prática educativa precisam, num dado momento, perceber se sua atuação profissional tem garantido a aprendizagem de seus alunos. Sobre este assunto, Tardif e Lessard (2007, p. 172) advertem-nos que, na maioria das vezes, "os professores não discutem, ou discutem muito raramente, teorias pedagógicas, menos ainda trocam críticas sobre sua própria atividade docente". E isto, de certa forma, compromete o desenvolvimento de um sistema educacional que queira atender a todos os alunos indistintamente.

No caso específico da atividade docente na Universidade Federal de Alagoas, percebemos que esta também não tem favorecido uma autoavaliação sobre o trabalho pedagógico realizado na instituição, muito menos tem favorecido um ensino inclusivo que contemple a diversidade. Ao contrário disso, os resultados mostram-nos certa resistência, por parte de alguns profissionais, em rever suas práticas pedagógicas e seus métodos de ensino para melhor atender as necessidades educacionais das pessoas com deficiência, como retrata o fragmento que se segue:

Não [sou a favor da inclusão], porque eu teria que reprocessar todo o trabalho dessa natureza, até o momento eu não pensei nessa percepção de alterar tudo para adaptar a um ou dois alunos [...] É complicado, você teria que rever todo o material pra eles, porque o material é de anos. (Professor Célio).

Esse recorte possibilita-nos entender que, muitas das vezes, o professor se exime de sua responsabilidade de garantir condições de ensino-aprendizagem adequadas para todos os seus alunos, principalmente para aqueles alunos que possuam algum tipo de deficiência. Eles parecem preferir permanecer em sua zona de conforto, isto é, estar em um mundo conhecido e seguro, mesmo sabendo que alguns desses alunos pudessem ser prejudicados pela ausência de metodologias ade- quadas às suas necessidades educacionais. Dessa forma, diante da inclusão educacional, cabe a todo docente pensar em um novo fazer pedagógico, que difere da prática convencional e de tamanho único - e que, por vezes, não serve sequer aos alunos considerados "não deficientes". Com isso, decorrerão melhores práticas de ensino, favorecendo a permanência das pessoas com deficiência com qualidade no sistema educacional.

Ademais, esses fragmentos fazem-nos refletir que a educação não pode continuar a ser pensada como uma mera mercadoria a que somente alguns poderão ter acesso. Mas que este é um direito fundamental de todas as pessoas. Todavia, os professores também precisam assumir que têm responsabilidades neste processo e devem refletir sobre a sua prática pedagógica, visto que esta tem um papel incontestável e de fundamental importância no cenário educacional, e por consequência no meio social (DRAGO, 2013; NOGUEIRA; NOGUEIRA, 2014).

No caso dos professores entrevistados da Universidade Federal de Alagoas, eles precisam ser preparados para lecionar nos cursos de formação de professores, pois os seus alunos serão futuramente os profissionais da Educação Básica e, possivelmente, também irão lecionar para alunos com deficiência. Neste sentido, os professores da UFAL, assim como outros docentes que atuam em cursos de licenciaturas, devem propiciar em seu trabalho docente, além de aulas inclusivas, momentos que contribuam para a formação profissional de seus alunos, no que se refere ao atendimento da diversidade em sala de aula em situações futuras de ensino.

Sobre a atuação profissional dos docentes da UFAL para promover aulas inclusivas que atendessem indistintamente a todos os seus alunos, pudemos constatar que alguns deles disseram ter tentado realizar escassas mas necessárias estratégias pedagógicas em suas aulas, com o intuito de garantir a permanência de seus alunos com deficiência na educação superior, bem como garantir a aprendizagem destes alunos. Vejamos como estas estratégias são descritas:

O texto que eu selecionei para a aula de hoje, eu tive a preocupação de trazer uma fotocópia ampliada, para garantir um tamanho que ele [aluno com deficiência visual] pudesse fazer a leitura. (Professor Marcos). 
Perguntei muitas vezes [se a aluna com deficiência auditiva tinha alguma dificuldade]. No primeiro semestre foi quando ela me disse que tinha esse problema. Ela disse: 'Professor, eu tenho esse problema e às vezes eu não consigo acompanhar a aula.' Eu disse: 'Minha filha, quando isso acontecer me diga porque aí eu repito [o que não for entendido] para você ou então eu vou mais devagar.' Depois eu tentei ir acompanhando isso, entendeu? Mas é muito complicado você gerenciar isso e estar lembrando inclusive. (Professor Emanuel).

Essas estratégias de ensino, descritas nos fragmentos acima, mostram-nos alguma iniciativa metodológica propostas por alguns docentes da UFAL para atender as necessidades educacionais especiais de seus alunos com deficiência. Esses excertos também exprimem algumas dificuldades que os docentes encontram para trabalhar com a inclusão de pessoas com deficiência em suas salas de aula, uma vez que esse processo é de sua inteira, total e exclusiva responsabilidade. Diante desta situação, acreditamos, entre outras coisas, que os órgãos diretivos da instituição (aqui estamos a nos referir à instituição particularmente pesquisada) não podem omitir-se de sua incumbência educacional e social - garantir ensino e aprendizagem para todos os alunos - e deixar o professor assumir a responsabilidade desse processo de inclusão de maneira individual.

Antes, entendemos que os gestores também necessitam chamar para si as responsabilidades de promover a inclusão dos alunos com deficiência nos seus espaços, propondo uma política interna em que estejam presentes a formação de professores e técnicos-administrativos, a organização de serviços de apoio, com recursos tecnológicos e humanos especializados, entre outros.

Vale ainda dizer que, no processo de inclusão, a boa vontade, ainda que de extrema relevância para uma prática educacional inclusiva, não é suficiente para garantir a participação efetiva de todos, sendo preciso, neste caso, desenvolver uma cultura institucional inclusiva que contemple o desenvolvimento profissional e a aquisição de saberes que viabilizem o atendimento das necessidades educacionais especiais das pessoas com deficiência. No caso específico da docência, é necessário que os docentes tenham conhecimentos específicos sobre as deficiências e de como estas pessoas aprendem, para promover uma educação que atenda efetivamente as diferenças, sem qualquer forma de exclusão (OLIVEIRA, 2014).

Entretanto, ainda que a inclusão requeira mudanças concretas na atividade docente, não podemos considerar que estas vieram a ocorrer, em sua totalidade, entre os professores participantes. Para que se possa ter ideia desta situação, um dos docentes desconsiderava a situação de um dos seus alunos com deficiência visual que, em certos momentos, precisava de tratamento diferenciado para garantir as mesmas possibilidades que os seus pares, que não possuíam uma deficiência visual. Por conta disso, o professor empregava com todos o mesmo recurso didático - no caso em específico, a escrita em lousa - e não dispunha de nenhum outro recurso alternativo para o aluno com baixa visão. Vejamos o que o professor disse:

Na aula, o aluno [com deficiência visual] disse: 'Professor [do curso de História], que palavra é essa?' E eu disse: 'E por que você não se aproxima pra ver [sentar em uma cadeira mais próxima]?' Porque não adiantava eu aumentar a letra, porque o quadro tem o espaço. As pessoas têm a deficiência e não querem admitir que a tem. (Professor Marcos).

Essa atitude docente permite-nos considerar que não convém mais os professores manterem as suas práticas pedagógicas homogêneas, meritocráticas e conservadoras, pois estas, em grande parte, contribuem apenas para a exclusão do aluno com deficiência no contexto acadêmico. Além disso, a pessoa com deficiência não pode ser vista como um fator que constitui uma marca de caráter negativo e pejorativo, utilizada como subterfúgio da omissão de novos fazeres docentes (SANTOS; MORATO, 2012).

Ao invés disso, é necessário que a docência, juntamente com toda a instituição educacional, busque novas respostas frente ao processo educativo às necessidades educacionais de todos os seus alunos. Caso contrário, a instituição enquadrar-se-á em um sistema de ensino impotente no que diz respeito à diferença, com uma forte tendência a esmurrar no fracasso (CASTRO, 2011; MOREIRA, 2014). Dessa forma, essas mudanças em uma perspectiva da educação inclusiva buscam a melhoria do siste- 
ma de ensino na educação superior, uma vez que permitem garantir de forma adequada o ingresso, a permanência e a conclusão do curso de nível superior de todos os alunos.

\section{CONSIDERAÇÕES FINAIS}

Considerando as experiências e os saberes dos docentes da Universidade Federal de Alagoas em relação ao atendimento das necessidades educacionais especiais de pessoas com deficiência, conseguimos compreender que estes docentes tiveram poucas experiências significativas com pessoas com deficiência. E, dentre estas limitadas experiências vivenciadas por tais docentes com pessoas com deficiência, destacamos que estas se concentraram basicamente no sistema educacional e nos últimos anos. Apenas dois docentes haviam vivenciado experiências diferentes - no círculo familiar e nas amizades. Compreendemos também que uma significativa parte destes docentes não acreditava no desenvolvimento dos alunos com deficiência, principalmente no que diz respeito às pessoas com deficiência intelectual, às pessoas com deficiência visual e, também, às pessoas com transtornos globais do desenvolvimento.

Apesar dessa indiferença que os docentes da UFAL atribuíram às potencialidades de desenvolvimento acadêmico dos universitários com deficiência, cabe ainda dizer que uma parte destes docentes ainda tentou realizar escassas e tímidas, mas necessárias, estratégias pedagógicas. Outros docentes ainda buscaram obter conhecimentos específicos, de forma superficial, acerca de metodologias, estratégias de ensino e métodos de avaliação, para melhor atender as diferenças de seus alunos. Mas, ao contrário do que se pode pensar, o que observamos foi uma fragilidade de tais docentes para gerenciar turmas que tinham pessoas com deficiência. Essa fragilidade pôde ser verificada quando os professores, mesmo com as formações recebidas/buscadas, não conseguiram atender de forma satisfatória as necessidades acadêmicas de seus alunos - trazendo implicações para suas respectivas formações profissionais.

Sendo assim, entendemos que alguns fatores contribuem(íram) para o comprometimento da atividade docente em relação às necessidades educacionais especiais de alunos com deficiência. Dentre estes fatores, enfatizamos em especial a ausência de uma formação pedagógica que contemple conhecimentos específicos acerca da educação inclusiva, a ausência de experiências de vida com pessoas com deficiência e o não respeito à diversidade humana e às singularidades existentes.

Diante disso, é necessário que a Universidade Federal de Alagoas programe e execute ações que contribuam para a inclusão da pessoa com deficiência em seu estabelecimento de ensino, como também os docentes da UFAL procurem suprir esta carência que acompanha a sua formação e, por sua vez, executem atividades pedagógicas mais consistentes, levando em consideração as diferenças existentes na instituição educacional. Dessa forma, a instituição estaria mais preparada para acolher a todos os alunos que estejam e que ingressem na universidade e garantir o sucesso na sua trajetória acadêmica.

Por fim, ainda que este tenha sido um estudo envolvendo uma única instituição, ele aponta para a necessidade de investir na formação pedagógica do professor universitário, e que essa formação permita-lhe respeitar e atender a diversidade do alunado. Essa tarefa torna-se ainda mais urgente nos cursos de licenciatura, visto serem estes os responsáveis pela formação das novas gerações de professores da educação básica brasileira.

\section{REFERÊNCIAS}

AMERICAN ASSOCIATION ON INTELLECTUAL AND DEVELOPMENTAL DISABILITIES (AAIDD). 11th Edition Implementation Committee to DSM-V ASD and Developmental Disorders Subgroup. ID Subcommittee Public Comments regarding Draft Definition of Intellectual Disability. Washington, 2010. Disponível em: $<\mathrm{http}$ //www.aaidd.org/intellectualdisabilitybook/content_3961.cfm?navID=270>. Acesso em: 03 out. 2010.

BARBOSA, M. O. A atividade docente e o atendimento das necessidades educacionais de universitários/ as com deficiência na Universidade Federal de Alagoas. 2011. 20f. Relatório de iniciação científica, Centro de 
Educação, Universidade Federal de Alagoas, Maceió, 2011.

BARDIN, L. Análise de conteúdo. São Paulo: Edições 70, 2011.

BERALDO, T. M. L. Formação de docentes que atuam na Educação Superior. Revista de Educação Pública, Cuiabá, v. 18, n. 36, p. 240, jan./abr. 2009.

BRASIL. Constituição Federal de 1988. Brasília, DF: Senado, 1988.

Portaria n. 1.793 de 27 de dezembro de 1994: recomendação: formação de recursos humanos em educação especial. Brasília, DF: MEC/CNE,1994. Disponível em: <http://portal.mec.gov.br/ arquivos/pdf/portaria1793. pdf $>$. Acesso em: 15 maio 2015.

Lei $\mathbf{n}^{\mathbf{0} 9.394}$, de 20 de dezembro de 1996. Estabelece as diretrizes e bases da educação nacional. Brasília, DF, 1996a. Disponível em: <http://www.planalto.gov.br/ccivil_03/leis/19394.htm>. Acesso em: 15 maio 2015.

Aviso Circular no 277, de 08 de maio de 1996. Brasília, DF, 1996b. Disponível em: <http://portal.mec. gov.br/arquivos/pdf/aviso_circular277.pdf $>$. Acesso em: 15 maio 2015.

Portaria $\mathbf{n}^{\mathbf{0}}$ 3.284, de 07 de novembro de 2003. Dispõe sobre requisitos de acessibilidade de pessoas portadoras de deficiências, para instruir os processos de autorização e de reconhecimento de cursos, e de credenciamento de instituições. Brasília, DF, 2003. Disponível em: <http://portal.mec.gov.br/sesu/arquivos/pdf/port3284. pdf $>$. Acesso em: 15 maio 2015.

Decreto $\mathbf{n}^{\circ}$ 5.626, de 22 de dezembro de 2005. Regulamenta a Lei no 10.436, de 24 de abril de 2002, que dispõe sobre a Língua Brasileira de Sinais - Libras, e o art. 18 da Lei no10.098, de 19 de dezembro de 2000. Brasília, DF, 2005. Disponível em: <http://www.planalto.gov.br/ccivil_03/_ato2004-2006/2005/decreto/d5626. htm>. Acesso em: 15 maio 2015.

Ministério da Educação. Política Nacional de Educação Especial na Perspectiva da Educação Inclusiva. Brasília, DF: MEC/CNE, 2008.

BUENO, J. G. S. Deficiência e ensino superior: balanço das dissertações e teses brasileiras (1987/2006). In: VICTOR, S. L.; DRAGO, R; CHICON, J. F. Educação inclusiva de crianças, adolescentes, jovens e adultos: avanços e desafios. Vitória: EDUFES, 2013. p. 255-272.

CALHEIROS, D.; BARBOSA, M.; FUMES, N. Formação do(a) professor(a) universitário(a) para o atendimento do(a) aluno(a) com deficiência. In: CONGRESSO ACADÊMICO DA UFAL, 4., 2009, Maceió. Anais... Maceió: UFAL, 2009. p. 01-03.

CASTRO, S. F. Inclusão e permanência de alunos com deficiência em universidades públicas brasileiras. 2011. 245 f. Tese (Doutorado em Educação Especial) - Programa de Pós-Graduação em Educação Especial, Universidade Federal de São Carlos (UFSCar), São Carlos, 2011.

CHACON, M. Formação de recursos humanos em educação especial: resposta das universidades à recomendação da Portaria Ministerial n 1.793. Revista Brasileira de Educação Especial, Marília, SP, v. 10, n. 3, p. 321-336, set./dez. 2004.

CRUZ, E.; COSTA, F. A. Formas e manifestações da transdisciplinaridade na produção científico-académica em Portugal. Revista Brasileira de Educação, Rio de Janeiro, v. 20, n. 60, p. 195-213, jan./mar. 2015.

DRAGO, R. A inclusão chega ao ensino superior: concepções inclusivistas de um grupo de profissionais de uma faculdade privada da Grande Vitória. In: VICTOR, S. L.; DRAGO, R;

CHICON, J. F. (Org.). Educação inclusiva de crianças, adolescentes, jovens e adultos: avanços e desafios. Vitória: EDUFES, 2013. p. 273-302.

DUEK, V. P. Educação Inclusive e formação continuada: contribuições dos casos de ensino para processos de aprendizagem e desenvolvimento profissional de professores. 2011. 349 f. Tese (Doutorado em Educação) - Programa de Pós-Graduação em Educação, Universidade Federal do Rio Grande do Norte (UFRN), Natal, 2011.

FLICK, U. Introdução à pesquisa qualitativa. 3. ed. Porto Alegre: Artmed, 2009.

FREIRE, P. Pedagogia da autonomia: saberes necessários à prática educativa. 43. ed. São Paulo: Paz e Terra, 2011.

GATI. B. A.; BARRETTO, S, S.; ANDRÉ, M. E. D. A. Políticas docentes no Brasil: um estado da arte. Brasília: 
UNESCO, 2011.

INSTITUTO NACIONAL DE ESTUDOS E PESQUISAS EDUCACIONAIS ANÍSIO TEIXEIRA(INEP). Censo da Educação Básica 2014. Brasília, DF, 2015.

MARQUES, L. S.; GOMES, C. Concordâncias/discordâncias acerca do processo inclusivo no Ensino Superior: um estudo exploratório. Revista Educação Especial, Santa Maria, RS, v. 27, n. 49, p. 313-326, maio/ago. 2014.

MATOS, S. N.; MENDES, E. G. A proposta de inclusão escolar no contexto nacional de implementação das políticas educacionais. Práxis Educacional (online), Vitória da Conquista, BA, v. 10, n. 16, p. 33-59, jul./dez. 2014. Disponível em: $<$ http://periodicos.uesb.br/index.php/praxis/article/viewFile/2889/2571>. Acesso em: 27 abr. 2011.

MOREIRA, L. C. Políticas inclusivas no Ensino Superior: da implantação à concretização. In: PIECZKOWSKI, T. M. Z.; NAUJORKS, M. I. (Org.). Educação, inclusão e acessibilidade: diferentes contextos. Chapecó, SC: Argos, 2014. p. 303-316.

NEUENFELDT, M. C. Formação de professores para o ensino superior: reflexões sobre a docência orientada. In: SEMINÁRIO NACIONAL DE FILOSOFIA E EDUCAÇÃO: CONFLUÊNCIAS, 2., 2006, Santa Maria. Anais.... Santa Maria: FACOS - UFSM, 2006. p. 01-07.

NOGUEIRA, L. F. Z. Inclusão de deficientes no ensino superior: o trabalho docente frente ao processo de inclusão. 2010. 91 f. Dissertação (Mestrado em Educação) - Programa de pós-graduação em educação, Universidade de Sorocaba, Sorocaba, SP, 2010.

NOGUEIRA, L. F. Z.; NOGUEIRA, E. J. Inclusão de deficientes no ensino superior: o trabalho docente frente ao processo de inclusão. Quaestio, Sorocaba, SP, v. 16, n. 2, p. 433-449, nov. 2014.

NOVAIS, G. Formação docente e inclusão escolar: ensinando do jeito que não aprendi? In: NOVAIS, G.; CICICLINI, G. (Org.). Formação docente e práticas pedagógicas: olhares que se entrelaçam. Belo Horizonte: FAPEMIG, 2010. p. 185-208.

NÓVOA, A. Os professores e as histórias da sua vida. In: NÓVOA, Antônio (Org.). Vidas de professores. Porto: Porto, 1992. p. 11-30.

OLIVEIRA, G. G. Neurociências e os processos educativos: um saber necessário na formação de professores. Educação Unisinos, São Leopoldo, RS, v. 18, n. 1, p. 13-24, jan./abr. 2014.

OLIVEIRA, L. Formação docente na escola inclusiva: diálogo como fio tecedor. Porto Alegre: Mediação, 2009.

OLIVEIRA, C. C.; VASCONCELLOS, M. M. M. A formação pedagógica institucional para a docência na Educação Superior. Interface, Botucatu, SP, v. 15, n. 39, p. 1011-1024, out./dez. 2011.

ORGANIZAÇÃO DAS NAÇÕES UNIDAS (ONU). Convenção sobre os Direitos das Pessoas com Deficiência. New York, 2006. Disponível em: <http://www.bengalalegal.com/convencao>. Acesso em: 08 jul. 2012.

ORGANIZAÇÃO DAS NAÇÕES UNIDADES PARA A EDUCAÇÃO, A CIÊNCIA E A CULTURA (UNESCO). Declaração de Salamanca. Sobre Princípios, Políticas e Práticas na área das Necessidades Educativas Especiais. Paris: UNESCO, 1994.

Declaração Mundial sobre Educação para Todos: plano de ação para satisfazer as necessidades básicas de aprendizagem. Jontiem, Tailândia, 1990.

PERES, M. R. A. et al. Formação docente e os desafios da prática reflexiva. Educação, Santa Maria, v. 38, n. 2 , p. 289-304, maio/ago. 2013.

PICCOLO, G. M.; MENDES, E. G. Contribuições a um pensar sociológico sobre a deficiência. Educação \& Sociedade, Campinas, SP, v. 34, n. 123, p. 459-475, abr./jun. 2013.

PLETSCH, M. D. A escolarização de pessoas com deficiência intelectual no Brasil: da institucionalização às políticas de inclusão (1973-2013). Arquivos Analíticos de Políticas Educativas, Arizona State University, v. 22 , n. 81, p. 01-29, ago. 2014.

PRIETO, R. G. Política de educação especial no Brasil: evolução das garantias legais. In: VICTOR, S. L.; DRAGO, R; CHICON, J. F. (Org.). Educação inclusiva de crianças, adolescentes, jovens e adultos: avanços e desafios. Vitória: EDUFES, 2013. p. 17-36. 
SANTOS, S. D. G. Autoconfrontação e o processo de inclusão: (re)vendo a atividade docente na educação superior. 2011. 131f. Dissertação (Mestrado em Educação Brasileira) - Centro de Educação, Universidade Federal de Alagoas (UFAB), Maceió, 2011.

SANTOS, S.; MORATO, P. Acertando o Passo! Falar de deficiência mental é um erro: deve falar-se de dificuldade intelectual e desenvolvimental (DID). Por quê? Revista Brasileira de Educação Especial, Marília, v. 18, n. 1, p. 3-16, jan./mar. 2012.

SILVA, A. S. Os saberes docentes para a prática pedagógica de alunos com necessidades educativas especiais na escola regular. 2014. 118 f. Dissertação (Mestrado em Educação) - Programa de Pós-Graduação em Educação, Universidade Estadual de Feira de Santana (UEFS), Feira de Santana, BA, 2014.

SILVA, I. C. M.; PLETSCH, M. D. A política de "educação inclusiva" no ensino técnico-profissional: resultados de um estudo de caso. Democratizar, Rio de Janeiro, v. 4, n. 1, maio/ago. 2010.

TARDIF, M. Saberes docentes e formação profissional. 8. ed. Petrópolis, RJ: Vozes, 2007.

TARDIF, M.; LESSARD, C. O trabalho docente: elementos para uma teoria da docência como profissões de interações humanas. 3 ed. Petrópolis: Vozes, 2007.

XAVIER, L. N. A construção social e histórica da profissão docente uma síntese necessária. Revista Brasileira de Educação, Rio de Janeiro, v. 19 n. 59, p. 827-849, out./dez. 2014.

YUNES, M. A. M.; SZYMANSKI, H. Entrevista reflexiva \& grounded-theory: estratégias metodológicas para compreensão da resiliência em famílias. Revista Interamericana de Psicología, Porto Alegre, v. 39, n. 3, p. 431438, dez. 2005.

Recebido em: 30.09 .2016

Aprovado em: 23.07.2016 